\title{
Systemic Inflammation and Cardiovascular Comorbidity in Psoriasis Patients: Causes and Consequences
}

\author{
Wolf-Henning Boehncke ${ }^{1,2 *}$ \\ ${ }^{1}$ Department of Pathology and Immunology, Faculty of Medicine, University of Geneva, Geneva, Switzerland, \\ ${ }^{2}$ Division of Dermatology and Venereology, Geneva University Hospitals, Geneva, Switzerland
}

OPEN ACCESS

Edited by:

Eva Reali,

Istituto Ortopedico Galeazzi

(IRCCS), Italy

Reviewed by:

Ralf J. Ludwig,

University of Lübeck, Germany ZhiQiang Yin,

First Affiliated Hospital of Nanjing Medical University, China

*Correspondence:

Wolf-Henning Boehncke wolf-henning.boehncke@hcuge.ch

Specialty section:

This article was submitted to Inflammation,

a section of the journal

Frontiers in Immunology

Received: 15 February 2018

Accepted: 07 March 2018

Published: 05 April 2018

Citation:

Boehncke W-H (2018) Systemic Inflammation and Cardiovascular Comorbidity in Psoriasis Patients:

Causes and Consequences.

Front. Immunol. 9:579. doi: 10.3389/fimmu.2018.00579
Psoriasis is a common inflammatory skin disease characterized by the appearance of red scaly plaques that can affect any part of the body. High prevalence, chronicity, disfiguration, disability, and associated comorbidity make it a challenge for clinicians of multiple specialties. Likewise, its complex pathogenesis, comprising inflammation, hyperproliferation, and angioneogenesis, intrigues numerous scientific disciplines, namely, immunology. From a clinical perspective, the severity of psoriasis is highlighted by its increased mortality, with cardiovascular diseases contributing the highest excess risk. From a scientific point of view, psoriasis has to be considered a systemic inflammatory condition, as blood biomarkers of inflammation are elevated and imaging techniques document sites of inflammation beyond the skin. While the association of psoriasis with cardiovascular diseases is now widely accepted, causes and consequences of this association are controversially discussed. This review comments on epidemiologic, genetic, and mechanistic studies that analyzed the relation between psoriasis and cardiovascular comorbidity. The hypothesis of psoriasis potentially being an independent cardiovascular risk factor, driving atherosclerosis via inflammationinduced endothelial dysfunction, will be discussed. Finally, consequences for the management of psoriasis with the objective to reduce the patients' excess cardiovascular risk will be pointed out.

Keywords: psoriasis, coronary heart disease, stroke, atherosclerosis, insulin resistance, endothelial dysfunction, mortality

\section{INTRODUCTION}

Psoriasis is among the few non-communicable diseases the World Health Organization identified as a major global health problem (1). It is a common inflammatory skin disease, affecting around $2 \%$ of the population in Western countries (2). Its clinical hallmark are red scaly plaques that can affect any part of the body, but preferentially appear over elbows and knees as well as on the scalp, the umbilical, and perianal region. These lesions reflect the principal pathogenetic mechanisms underlying psoriasis, namely, inflammation, hyperproliferation, and angioneogenesis. To date, psoriasis is considered an immune-mediated disease, exhibiting an intense cross talk between components of the innate and the adaptive immune system, which then trigger the epidermal changes (3). Psoriatic inflammation goes more than skin deep, as signs of inflammation can readily be detected at sites outside the skin (4). 
Comorbidity is a common feature of many immunemediated inflammatory diseases across different medical specialties, including model diseases such as rheumatoid arthritis (5), inflammatory bowel disease (6), or multiple sclerosis (7). A wealth of data documents the association of psoriasis with numerous comorbid diseases, including cardiometabolic, gastrointestinal, and kidney diseases as well as malignancies, infections, and mood disorders (8). To this end, it is still controversial whether psoriatic arthritis should be considered an extracutaneous manifestation of psoriasis or as a separate entity, and thus comorbidity (9). Among the comorbid conditions, cardiovascular diseases are of particular importance, as they often directly impact the patients' mortality (10).

In the case of rheumatoid arthritis, currently available evidence is strong enough to allow the issue of recommendations that substantially change prevention and treatment goals for cardiovascular risk factors in these patients (11). And while the association with cardiovascular diseases also among psoriasis patients is now widely accepted, causes and consequences of this association are controversially discussed (12-14). This review comments on epidemiologic, genetic, and mechanistic studies that analyzed the relation between psoriasis and cardiovascular comorbidity. The hypothesis of psoriasis potentially being an independent cardiovascular risk factor, driving atherosclerosis via inflammation-induced endothelial dysfunction, will be discussed. Finally, consequences for the management of psoriasis with the objective to reduce the patients' excess cardiovascular risk will be pointed out.

\section{EPIDEMIOLOGY}

One of the first systematic analyses on disease concomitance based on more than 40,000 cases identified an association of psoriasis not only with cardiovascular disease but also with diseases that represent risk factors for atherosclerosis, such as diabetes mellitus or obesity. The authors concluded that a distinct pattern of associated diseases exists in patients with psoriasis and suggest a genetically determined selection (15). Since then, multiple epidemiologic studies have addressed the issue of cardiovascular comorbidity in psoriasis patients. And while some groups concluded that such a link does not exist (16-18), many others were able to reproduce this association recently summarized elsewhere $(8,19)$ (Table 1). Based on the currently available evidence, most experts agree that the association of psoriasis with cardiovascular comorbidity is real (20). This is also reflected by and justifies the inclusion of advice on the management of psoriasis patients with such comorbidities in guidelines and treatment recommendations $(21,22)$.

The fact that cardiovascular diseases are associated with psoriasis leads to the question on why that might be so. A strong argument in favor of an indirect link comes from the observation that psoriasis is associated with numerous conditions representing major cardiovascular risk factors in their own right (Table 2). In fact, the very first publication on psoriasis comorbidity reported an association with diabetes mellitus as early as 1897 (31). Also, the study by Henseler and Christophers cited above documents diabetes mellitus and obesity as concomitant conditions (15). Finally, Takeshita et al. recently summarized the evidence for obesity, hypertension, diabetes mellitus, dyslipidemia, and the metabolic syndrome as comorbid diseases in psoriasis (8), with the metabolic syndrome essentially representing the combined appearance of obesity, hypertension, insulin resistance, and dyslipidemia (32). These conditions are not only well-established major cardiovascular risk factors and therefore incorporated in the Framingham's Cardiovascular Disease Risk Scores used to predict cardiovascular risk in the general population (33), some of them, namely, smoking (34) and obesity (35), are also risk factors for the development of psoriasis.

TABLE 1 | Summary of studies analyzing the association between psoriasis and major adverse cardiovascular events.

\begin{tabular}{|c|c|c|}
\hline Reference & Study characteristics & Key finding \\
\hline Dowlatshahi et al. (16) & $\begin{array}{l}\text { Population-based study ( } 262 \text { patients with mostly } \\
\text { mild psoriasis, and 8,009 controls) }\end{array}$ & No increased risk for cardiovascular events \\
\hline Parisi et al. (17) & Cohort study (48,000 patients and 200,000 controls) & No association of psoriasis with cardiovascular disease \\
\hline Egeberg et al. (18) & Nationwide cohort study (adult population of Denmark) & Slight increase of myocardial infarction in patients with severe psoriasis \\
\hline Armstrong et al. (23) & $\begin{array}{l}\text { Systematic review and meta-analysis ( } 220,000 \text { patients } \\
\text { and } 10 \text { mio controls) }\end{array}$ & $\begin{array}{l}\text { Increased risk for myocardial infarction, stroke, and cardiovascular mortality } \\
\text { among psoriasis patients }\end{array}$ \\
\hline Gaeta et al. (24) & Meta-analysis ( 1.8 mio patients and 43 mio controls) & $\begin{array}{l}\text { Increased risk for myocardial infarction and cardiovascular mortality among } \\
\text { psoriasis patients }\end{array}$ \\
\hline Gu et al. (25) & Meta-analysis of cohort studies (6.2 mio individuals overall) & $\begin{array}{l}\text { Increased risk for myocardial infarction, stroke, and cardiovascular mortality } \\
\text { among psoriasis patients }\end{array}$ \\
\hline Horreau et al. (26) & $\begin{array}{l}\text { Systematic literature review }(324,000 \text { patients and } \\
5.3 \text { mio controls) }\end{array}$ & Increased risk for myocardial infarction and stroke among psoriasis patients \\
\hline Miller et al. (27) & Meta-analysis (500,000 patients and 29 mio controls) & Increased risk for cardiovascular disease among psoriasis patients \\
\hline Pietrzak et al. (28) & Review (360,000 patients and 9.2 mio controls) & Increased risk for cardiovascular events among psoriasis patients \\
\hline Samarasekera et al. (29) & $\begin{array}{l}\text { Systematic review and meta-analysis }(480,000 \text { patients } \\
\text { and } 10 \text { mio controls) }\end{array}$ & $\begin{array}{l}\text { Increased risk for myocardial infarction, stroke, and cardiovascular mortality } \\
\text { among psoriasis patients }\end{array}$ \\
\hline Xu et al. (30) & $\begin{array}{l}\text { Meta-analysis of cohort studies (326,000 patients and } \\
5.2 \text { mio controls) }\end{array}$ & Increased risk for myocardial infarction and stroke among psoriasis patients \\
\hline
\end{tabular}


TABLE 2 | Synopsis of arguments in favor or against the hypothesis of psoriasis representing an independent cardiovascular risk factor.

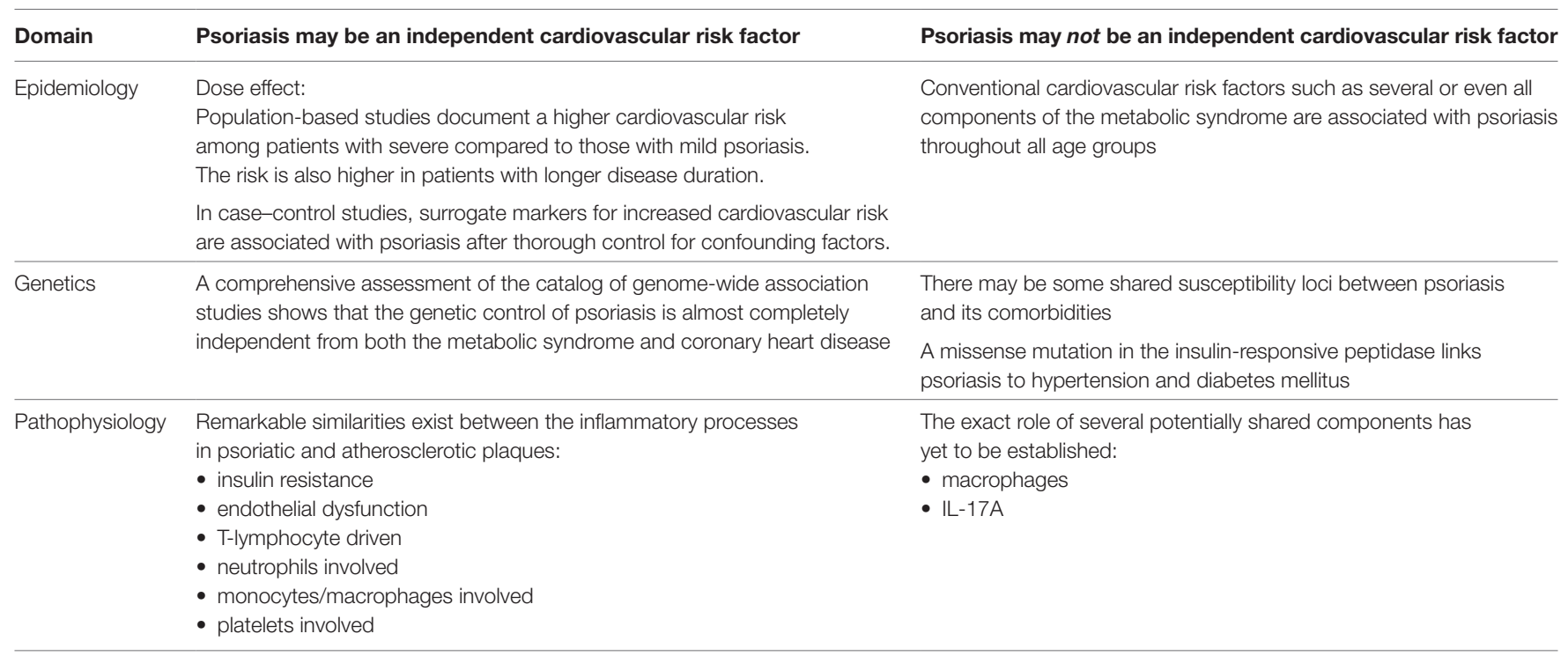

Evidence in favor of psoriasis as an independent cardiovascular risk factor comes from studies showing a "dose effect" of psoriasis on the patients' cardiovascular risk (Table 2). A landmark study in this regard was conducted by Gelfand et al. who used the General Practice Research Database from 1987 to 2002, comprising prospective data collected from general practitioners in Great Britain. After adjusting for major cardiovascular risk factors, such as hypertension, diabetes mellitus, and hyperlipidemia, they found a slightly elevated adjusted relative risk for myocardial infarction among patients with mild psoriasis, and a substantially elevated adjusted relative risk among patients with severe psoriasis (36). Two meta-analyses also came to the conclusion that the cardiovascular risk of psoriasis patients correlates with the severity of their disease $(29,23)$. In line with this hypothesis, longer duration of psoriasis has also been associated with increased cardiovascular risk for the patients $(37,38)$. Another landmark study was performed by Ludwig et al. who quantified coronary artery calcification via CT scans, using the well-established Agatston score, among hospitalized psoriasis patients, thus suffering from severe psoriasis (39). Their scores were compared to controls matched for all major cardiovascular risk factors. The study showed highly significantly elevated coronary artery calcification, so that the study had to be stopped before the originally calculated number of patients had been included. This observation is even more alarming, as only patients with a negative history for current or previous heart problems were included.

The clinical relevance of psoriasis as an independent cardiovascular risk factor was quantified by Mehta et al. in a cohort study of severe psoriasis patients. There, the attributable risk of severe psoriasis on major cardiovascular events, i.e., namely, myocardial infarction and stroke, over a 10-year period was found to be around 6\% (40). Others found the increased risk of such events associated with psoriasis to be comparable with that conferred by diabetes mellitus alone (41) or by rheumatoid arthritis (42). This is remarkable as the former is a well-accepted major cardiovascular risk factor, and the association of the latter with an increased cardiovascular risk already led to specific recommendations on how to address this extra risk, as pointed out above.

Taken together, despite few studies that did not show statistically significant associations between psoriasis and major cardiovascular events, a majority of studies using different methodical approaches suggests not only an association of psoriasis with cardiovascular diseases but also provides evidence for psoriasis as an independent cardiovascular risk factor (Table 2).

Noteworthy, chronic skin inflammation as such is not sufficient to explain the role of psoriasis as an independent cardiovascular risk factor, as a recent systematic review and meta-analysis failed to provide evidence for atopic dermatitis, another common chronic inflammatory skin disease, exhibiting comparable effects (43). A major epidemiologic study documented even the inverse phenomenon, namely, a rather significantly decreased risk for myocardial infarction, stroke, or cardiovascular death (44). Therefore, genetic and pathogenetic analyses are needed to understand this association.

\section{GENETICS}

One possibility to explain the association of psoriasis with its comorbid conditions in general and cardiovascular disease in particular is that these entities share common genetics. A genetic predisposition of psoriasis can already be postulated based on the facts that many patients have a positive family history and that the concordance rate among monozygotic twins is much higher compared to dizygotic twins (45). The first psoriasis susceptibility locus (PSORS-1) identified is located on the short arm of chromosome 6 in the region coding for major histocompatibility complex (MHC) molecules. It is still the most reproducible among all PSORS loci identified and may explain up to $50 \%$ of the heritability of psoriasis (46). Namely genome-wide association 
studies (GWASs) shed more light on the genetics of psoriasis and allowed to identify at least 50 regions on the human genome which harbor at least 1 and sometimes more than 1 potential candidate gene associated with psoriasis. This database allows to group the respective genes according to pathways, with antigen presentation, interleukin-23 (IL-23) signaling, T-lymphocyte development and polarization, innate immunity, and negative regulators of immune responses as the key axes (47).

Following up on the notion that chronic skin inflammation as such does not suffice to explain increased cardiovascular risk, a GWAS showed some overlap between susceptibility loci for psoriasis and atopic dermatitis. This association was mediated by a combination of shared and opposing alleles, with the most significant effects operating in opposing directions, thus arguing in favor of distinct pathogenetic pathways of these diseases (48). This notion is supported by a much smaller study from Japan that observed only marginal associations between atopic dermatitis and susceptibility single-nucleotide polymorphisms for psoriasis (49). By contrast, rheumatoid arthritis as another chronic inflammatory disease with known cardiovascular comorbidity does exhibit a genetic architecture not too different from psoriasis: genetic variants in the $\mathrm{MHC}$ region account for more than $60 \%$ of the known genetic heritability of rheumatoid arthritis. Other associated genes are involved in the function of T-lymphocytes and monocytes representing the adaptive and the innate immune system, respectively. 35 rheumatoid arthritis risk loci gene products can be mapped to signaling pathways in T-lymphocytes and antigen-presenting cells (50). These include components of the tumor necrosis factor alpha (TNF- $\alpha$ ) signaling cascade, the potential relevance of this finding will be discussed below.

Genetic variation and pathways in atherosclerosis do not show obvious overlap with the genetic signature of psoriasis or rheumatoid arthritis. Kessler et al. recently assigned 30 of 65 loci associated with coronary artery disease to 6 pathways with known pathophysiological roles in this disease, the function of the other 35 candidate genes is not sufficiently known to allow allocation to a particular pathway. These six pathways comprise inflammation, triglycerides, LDL cholesterol, blood pressure, vascular remodeling, and nitric oxide signaling (51).

Several groups have further analyzed the hypothesis of psoriasis and its comorbidities being genetically linked, following up on the observation that GWASs have shown overlap in the genetic susceptibility to different pathologies, namely, immunemediated diseases (52). Ellinghaus et al. identified seven shared susceptibility loci for psoriasis and Crohn's disease; they went on to demonstrate a genetic overlap between five seronegative inflammatory diseases, namely psoriasis, Crohn's disease, ankylosing spondylitis, primary sclerosing cholangitis, and ulcerative colitis $(53,54)$. An observation pointing toward a genetic link between psoriasis and cardiovascular comorbidity was made by Cheng et al. who interpreted a missense mutation in the insulin-responsive aminopeptidase LNPEP as a potential link, namely between psoriasis, hypertension, and diabetes mellitus (55) (Table 2). The importance of insulin resistance in this context will be discussed in detail below. On the other hand, a comprehensive assessment of the catalog of GWASs by
Gupta et al. shows that the genetic control of psoriasis is almost completely independent from both the metabolic syndrome and coronary heart disease (Table 2). To prove reliability of this approach, the authors were able to identified 10 common loci for the metabolic syndrome and coronary heart disease, using exactly the same data set (56).

Taken together, although some genetic overlap between psoriasis and several of its comorbid conditions exists, the observed association of psoriasis with cardiovascular comorbidity cannot satisfyingly be explained by shared genetics (Table 2).

\section{PATHOGENESIS}

\section{Common Pathways of Psoriatic and Atherosclerotic Plaque Formation}

To this end, epidemiological evidence in favor of psoriasis being associated with cardiovascular comorbidity and potentially functioning as an independent cardiovascular risk factor has been summarized. As genetic overlap cannot satisfyingly explain the excess cardiovascular risk of patients with severe psoriasis, mechanistic studies are needed to further clarify the link.

Often, animal models are a good starting point to unravel pathogenetic mechanisms. With regard to psoriasis, older models often highlighted the role of the adaptive immune system (57), while novel approaches such as mannan-induced psoriasis shed more light on the crucial role of the innate immune system (58). Few studies have been performed to analyze the link between psoriasis and its cardiovascular comorbidity. One such approach takes advantage of the capacity of the TLR7 agonist imiquimod to induce a psoriasis-like inflammation in murine skin. Jin et al. succeeded in inducing a state of systemic inflammation through topical application of imiquimod onto interleukin-10-deficient mice, but noticed a decrease of body weight in these mice, while psoriasis patients show a trend toward obesity (59). Shibata et al. studied imiquimod-induced psoriasiform inflammation in mice deficient of adiponectin, an anti-inflammatory adipokine, and found a more severe phenotype in these knockout mice. Furthermore, intraperitoneal injections of adiponectin had a therapeutic effect in adiponectin knockout mice (60). While this study explored an indirect link between psoriasis and cardiovascular disease via metabolic factors, the only direct link the author is aware of comes from a study in the type-II collagenspecific antibody-induced psoriatic arthritis model. Using this model, Sherlock et al. demonstrated that IL-23 drives inflammation in the aortic root through activation of $\mathrm{CD}^{+} \mathrm{CD}^{-} \mathrm{CD}^{-}$ T-lymphocytes (61).

Atherosclerosis as a key process in cardiovascular diseases has long been recognized as an inflammation-driven phenomenon $(62,63)$. This is also true for psoriasis $(64,65)$. The cardiologist Späh was among the first who discussed a potentially common inflammatory pathway and the idea of an integrated treatment approach (66). He stressed altered endothelial function and subsequent recruitment of leukocytes, primarily T-lymphocytes, to developing lesions as a shared early step in the process of plaque formation in atherosclerosis and psoriasis. Lymphocyte extravasation has indeed been studied in detail with the intention 
to develop targeted therapies for psoriasis, but to date, none of the potential candidates was found to be sufficiently effective to validate development into a marketed drug $(67,68)$. Meanwhile, many more shared mechanisms of atherosclerosis and psoriasis have been studied in detail.

Elaborating on the observations described above, a role namely for T-helper-1 lymphocytes (TH1 lymphocytes) has been established in atherosclerosis as well as psoriasis (Table 2). Although TH1 as well as TH2 lymphocyte responses can contribute to atherosclerosis, several lines of evidence suggest a predominant role of TH1 lymphocytes. These include the TH1 phenotype and function of most T-cell clones derived from atherosclerotic plaques as well as immunohistochemical studies on such plaques (69-71). Subsequently, high circulating levels of TH17 lymphocytes and IL-17 in patients with acute coronary syndrome, a positive correlation of IL-17 with levels of highsensitivity C-reactive protein and IL-6 (predicting an increased risk of myocardial infarction) in those patients, and the observation that IL-17 inhibition in mice significantly reduces the size of atherosclerotic plaques, were all interpreted as indicators for a role of TH17 lymphocytes in atherosclerosis (72-74). Similarly, psoriasis was initially thought to be a prototypical TH1 lymphocyte-mediated disease, with these cells activating macrophages, neutrophils and $\mathrm{CD}^{+}$cytotoxic lymphocytes (75). Then, the role of TH17 lymphocytes was stressed in the light of clinical studies documenting the high clinical efficacy of therapies targeting the IL-17 pathway (76).

While the role of the adaptive immune system in the pathogenesis of psoriasis has been thoroughly investigated ever since the accidental observation of the therapeutic efficacy of cyclosporine A in 1979 (77), interest in the important role of the innate immune system has only recently experienced a renaissance (Table 2). Evidence for the contribution of neutrophils, which are predominant in pustular forms, but readily detectable also in chronic plaque type psoriasis, where they form the so-called Munro's abscesses within the epidermis, comes from in vivo studies as well as organotypic 3D models and has recently been reviewed elsewhere (78). Further supporting the role of neutrophils is the clinical observation by Reich et al., who reported that psoriasis treatment with the anti-IL17A antibody secukinumab resulted in the near total elimination of intraepidermal IL-17-positive neutrophils as an early therapeutic effect (79). Neutrophils are equally important in atherosclerosis, as they interact with damaged endothelium, augment leukocyte recruitment via secretion of chemotactic mediators, and promote the development of foam cells, a macrophage subset driving atherosclerosis (80). Neutrophil localization to developing atherosclerotic plaques has been demonstrated in mouse models $(81,82)$ and human atherosclerotic lesions (83); their presence in occlusive thrombi and culprit lesions of acute coronary syndrome patients suggests a role in atherosclerotic progression (84).

As for neutrophils, involvement of monocytes and macrophages has readily been demonstrated in both diseases (Table 2). These are regularly detectable in psoriatic lesions (85). Using a mouse model where the psoriatic phenotype is induced by topical application of the immunomodulator imiquimod, Costa et al. demonstrated that induction of the phenotype depends exclusively on hematopoietic cells. Using conditional knockout mouse strains, the active contribution of monocytes and macrophages on disease propagation and exacerbation was shown (86). With regard to atherosclerosis, Tabas and Lichtman recently reviewed how macrophages can be programmed for functions on a spectrum from inflammatory and host defense to resolution and repair in atherosclerotic plaques (87). In general, inflammatory macrophages carry out processes that promote atherosclerosis progression, including plaque necrosis and thinning of a protective fibrous cap. By contrast, resolving macrophages carry out functions that can suppress plaque progression and promote plaque regression, including clearing dead cells and secreting collagen that can form a protective scar over the lesion (88).

Besides these vigorously studied cells of the adaptive immune system, platelets seem to also actively contribute to atherosclerosis and psoriasis (Table 2). Platelets are widely known to have prominent functions in hemostasis and thrombosis, but their involvement in immune and inflammatory processes is now more and more recognized (89). Their potential to influence such process is not surprising, given their capacity to release a plethora of mediators and to interact with numerous cells and tissues through a variety of adhesion molecules. In psoriasis, platelet activation can be used to monitor disease activity through quantification of platelet activation markers in the patients' blood (90). Mechanistically, it is thought that activated platelets facilitate leukocyte extravasation (91). Similar effects link platelets to atherosclerosis $(92,93)$. The clinically relevant role of platelets in this context is underlined by the success of platelet inhibitory drugs in treating and preventing acute arterial thromboembolic events (94).

In recent years, a factor attracting particular attention in the context of psoriatic as well as atherosclerotic inflammation is IL-17A. Its role as a major driver of psoriatic inflammation is now well accepted and underlined by the numerous lines of evidence, including the development of a psoriatic phenotype in mice overexpressing IL-17A in the epidermis (95), or the high efficacy of IL-17A-blocking biologics in the treatment of psoriasis (96). By contrast, deciphering the exact role of IL-17A in atherosclerosis remains a challenging task (Table 2). Numerous studies documented pro-atherogenic effects. For example, in a hypercholesterolemic animal model, IL-17A inhibition reduced atheroma area and stenosis. At the molecular level, expression of the chemokine CCL5 (CC chemokine ligand 5), the cytokines IL-6 and TNF- $\alpha$, several adhesion molecules including vascular cell adhesion molecule 1, and the pro-thrombotic molecule TF was reduced (74). Complementary experiments were conducted in murine models, where addition of exogenous IL-17A-stimulated pathological changes associated with increased plaque instability, while IL-17A inhibition resulted in regression of atherosclerosis (97-99). Ex vivo studies on human plaque fragments showed that exposure to IL-17A induced pro-inflammatory, pro-thrombotic, plaque destabilizing, and cell-attracting effects (100). On the other hand, there is also some evidence suggesting that IL-17A may have anti-atherosclerotic effects, as another mouse model characterized by increased IL-17A expression showed significantly smaller atherosclerotic lesions. In the same publication, 
an association between IL-17A expression and plaque stability in human carotid artery plaques was reported (101). Moreover, a study from Simon et al. on almost 1,000 patients with acute myocardial infarction demonstrated that low serum levels of IL-17A are associated with a higher risk for major cardiovascular events (102). Overall, many experts lean toward the concept of IL-17A being primarily pro-atherogenic, although some uncertainty persists.

\section{Psoriatic Inflammation as a Driver for Atherosclerosis}

Thus, over the last decade, multiple shared pathogenetic mechanisms have been identified in psoriatic and atherosclerotic plaque formation. These similarities do not, however, explain why psoriasis might actually represent an independent cardiovascular risk factor, as suggested by the majority of epidemiologic studies. Of major importance in this regard was the notion that psoriasis cannot be regarded as isolated cutaneous inflammation, but rather represents a chronic systemic inflammatory disease. To this end, several groups have identified biomarkers of inflammation in the blood of psoriasis patients which correlate with psoriasis severity, such as C-reactive protein (103), erythrocyte sedimentation rate (104), and the platelet activation marker P-selectin (90). Documentation of vascular inflammation through (18)F-fluorodeoxyglucose positron emission tomography computed tomography (PET-CT) in psoriasis patients, pioneered by Mehta and co-workers, points into the same direction (4). More recently, the group demonstrated that psoriasis severity associates with aortic vascular inflammation detected by that method (93), suggesting that psoriatic inflammation affects blood vessels and induces inflammation in the vessel walls. Studies in mouse models confirm that chronic skin-specific inflammation can indeed induce vascular inflammation (94).

The pathogenetic link between psoriasis and cardiovascular comorbidity is likely provided through insulin resistance and endothelial dysfunction, as these are known drivers for atherosclerosis (105). Insulin resistance is typically defined as decreased sensitivity to metabolic actions of insulin that promote glucose disposal. This is not only an important feature of diabetes mellitus but also a prominent component of cardiovascular disorders, which are characterized by endothelial dysfunction (106). Conversely, endothelial dysfunction is also present in diabetes mellitus (107). In addition to its essential metabolic actions, insulin has important vascular actions that involve stimulation of the production of nitric oxide from endothelium, leading to vasodilation (Figure 1A). This effect has metabolic consequences, too, as increased blood flow ultimately leads to augmented glucose disposal in skeletal muscle (108). On the other hand, insulin signaling in endothelial cells regulates secretion of the vasoconstricting factor endothelin-1. Inflammation shifts this equilibrium as it induces insulin resistance via cytokines, which alter insulin signaling in endothelial cells, ultimately reducing the production of vasodilating nitric oxide and inducing endothelial dysfunction (109) (Figure 1B).

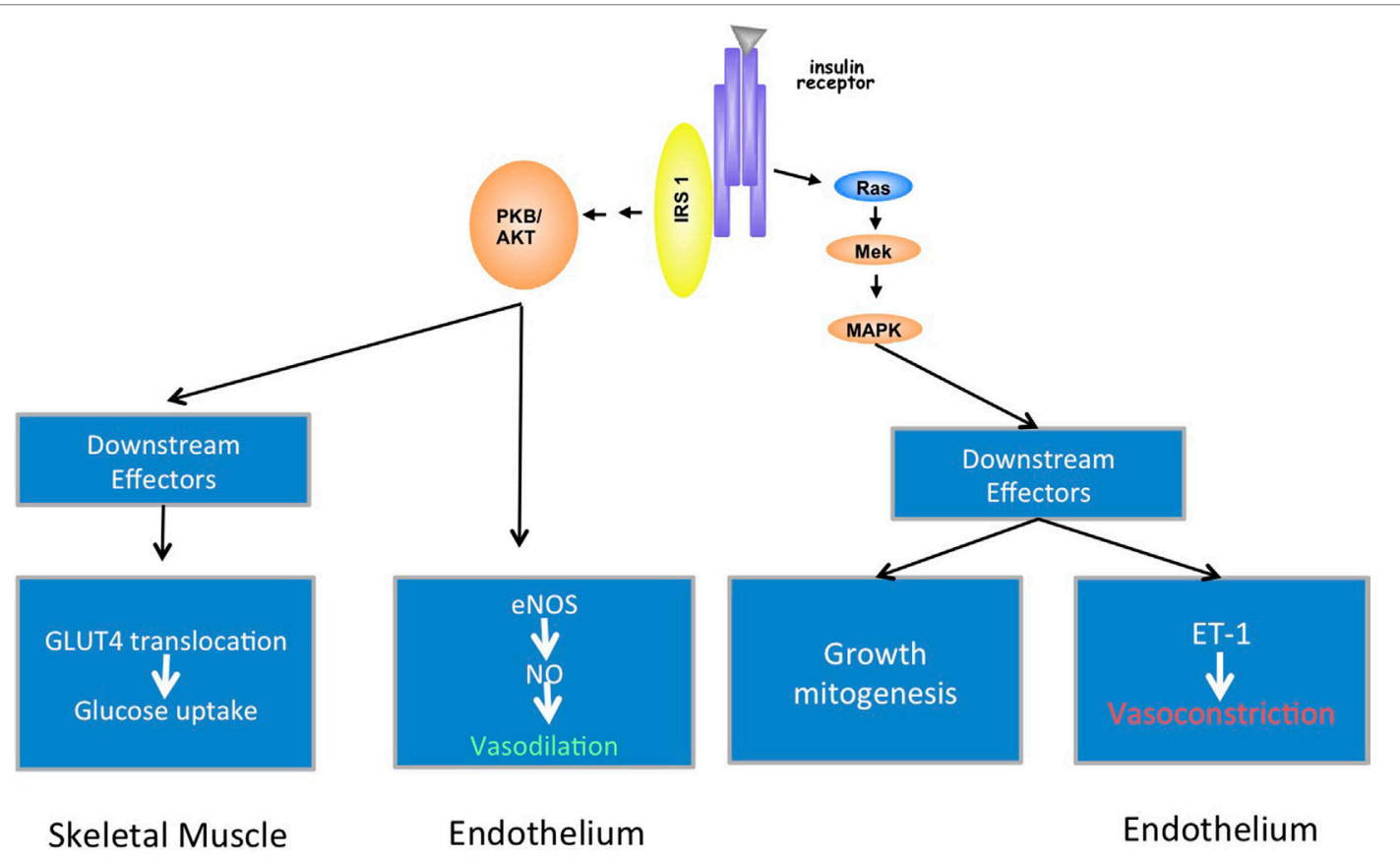

FIGURE 1 | Metabolic and vascular effects of insulin. Under physiologic conditions, the activated insulin receptor on endothelial cells leads to phosphorylation of endothelial nitric oxide synthase (eNOS) via activation of insulin receptor substrate (IRS) and phosphoinositide-3-kinase (a). This results in vasodilation via NO production. This branch also regulates GLUT4 translocation and glucose uptake in muscle cells. The mitogen-activated protein kinase (MAPK) pathway controls secretion of vasoconstrictive ET-1 in endothelial cells, and cell growth and mitogenesis in cells at large. Inflammation reduces NO production via blocking insulin receptor signaling at the level of the IRS-1 (b). 
Noteworthy, TNF- $\alpha$, a central cytokine in the pathogenesis of many chronic inflammatory diseases including psoriasis, is a major insulin antagonist (110).

The concept of the "psoriatic march" provides a framework to explain how psoriatic inflammation drives cardiovascular comorbidity via atherosclerosis independently from the presence of additional cardiovascular risk factors $(111,112)$ (Figure 2). According to this concept, psoriasis is a chronic systemic inflammatory disorder, as evidenced by elevated biomarkers of systemic inflammation. Noteworthy, not only classical markers for systemic inflammation have been shown to be elevated but also resistin and leptin $(113,114)$. These belong to a family of mediators secreted by adipocytes called adipokines. Resistin and leptin are insulin antagonizing adipokines. Collectively, the adipokine milieu in the blood of psoriasis patients is strikingly similar to that of prediabetic individuals and is a hint toward a state of insulin resistance. The diagnosis of insulin resistance is based on the so-called homeostasis model assessment of insulin resistance (HOMA-IR) index, calculated on the basis of a blood test, or an oral glucose tolerance test $(115,116)$. Using these approaches, two cross-sectional studies demonstrated that psoriasis patients exhibit insulin resistance at clinical levels $(113,117)$. Besides the insulin-antagonizing effects, numerous adipokines in general and leptin in particular may drive atherosclerosis through immunomodulation, including the upregulation of adhesion molecules on endothelial cells (118). At the level of endothelial cells, insulin resistance is thought to induce endothelial dysfunction via the pathway described above, resulting in vascular stiffness at the functional level. Indeed, several groups found evidence for endothelial dysfunction, using ultrasound methods. In particular, flowmediated vascular dilation was impaired (119-122). In one of these studies, insulin resistance was assessed as well via the HOMA-IR and found to be significantly higher when compared to non-psoriatic controls, again stressing the link between insulin resistance and endothelial dysfunction in psoriasis (122). This cascade drives atherosclerosis, which ultimately causes cardiovascular diseases such as myocardial infarction and stroke.

Although not in the focus of this review, it is interesting to note that inflammation-induced insulin resistance may well help to explain the altered epidermal homeostasis observed in the epidermis of psoriatic plaques $(123,124)$, a phenomenon that might have implications beyond psoriasis (125).

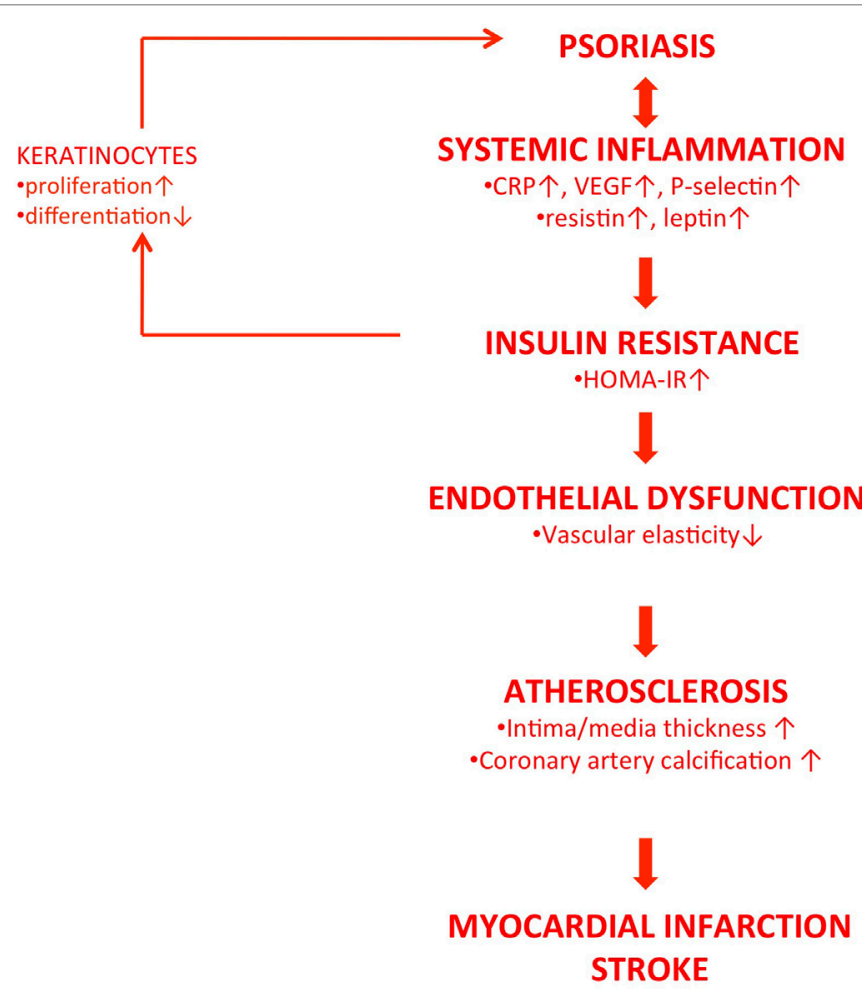

FIGURE 2 | The concept of the "psoriatic march." This hypothesis suggests that psoriasis is a systemic inflammatory condition, as numerous biomarkers of inflammation are elevated in the patients' blood compartment. Functional consequences are insulin resistance, evidenced by an increased HOMA-IR (homeostasis assessment of insulin resistance), and endothelial dysfunction, resulting in increased vascular stiffness. This provides the basis for atherosclerosis, observable through analysis of vessel wall composition via CTs or ultrasound. Depending on the sites of atherosclerosis, major cardiovascular events such as myocardial infarction and stroke result from this. This "backbone" (red, bold) may be developed further by adding additional "modules": insulin resistance has been shown to alter epidermal homeostasis (red, fine). Obesity, causing a state of systemic inflammation as well, is a known risk factor for psoriasis and may induce the phenotype (orange, bold). Whether systemic anti-inflammatory therapy is capable of reducing the patients' cardiovascular risk through reducing insulin resistance and endothelial dysfunction is still a matter of debate (green). 


\section{CONSEQUENCES FOR THE MANAGEMENT OF PSORIASIS}

\section{Monitoring}

Most observations discussed so far support the notion that cardiovascular comorbidity is a clinically relevant problem for patients suffering from severe psoriasis. In spite of this, several studies document that these patients are not adequately monitored and treated for cardiovascular risk factors. A survey conducted between October 2010 and April 2011 among primary care physicians and cardiologists showed that most of the responding physicians (251 of 1,200 questionnaires sent out were returned) did not routinely screen psoriasis patients for cardiovascular risk factors (126). A cross-sectional study based on National Ambulatory Medical Care Survey data from 2005 to 2009 demonstrated that less than half of the psoriasis patients were screened for at least one cardiovascular risk factor (127). Finally, in a cross-sectional study of patients with hypertension in Great Britain, psoriasis patients were more likely to have uncontrolled hypertension compared with nonpsoriatic individuals (128). This is in contrast to recommendations from numerous organizations and societies, who unanimously suggest such a screening (129-131). Takeshita et al. recently summarized what most experts currently agree upon, much of it being identical to what is comprised in current recommendations for the general adult population $(132,133)$ : traditional cardiovascular risk factors should be evaluated. These include total and high-density lipoprotein cholesterol, systolic blood pressure, use of antihypertensive therapy, diabetes, and current smoking. In addition, lifestyle interventions, such as weight loss and smoking cessation, should be encouraged among patients who are obese and who are current smokers, respectively. A controlled clinical trial published a decade ago already showed the potential advantages of a more comprehensive approach to psoriasis treatment, as obese patients with moderate-to-severe psoriasis had a better response to low-dose cyclosporine $\mathrm{A}$ if a calorie-reduced diet was included in their treatment regimen (134).

\section{Prevention}

The state of chronic systemic inflammation in psoriasis may at least contribute to atherosclerosis via insulin resistance and endothelial dysfunction and therefore be partially responsible for the increased cardiovascular risk of patients with severe psoriasis. This raises the question whether continuous systemic anti-inflammatory treatments may help to reduce this excess risk. Recently, data from the CANTOS trial suggest that this is principally feasible. That trial evaluated the efficacy of the interleukin-1 $\beta$-blocking antibody canakinumab in more than 10,000 patients with previous myocardial infarction and a highsensitivity C-reactive protein level of $2 \mathrm{mg}$ or more per liter on nonfatal myocardial infarction, nonfatal stroke, or cardiovascular death. At a median follow-up of 3.7 years, the incidence rate was 4.50 events per 100 patient-years in the placebo-group, and between 3.86 and 4.11 events per 100 patient-years in the different canakinumab dosing groups. Thus, the trial documented a small, but statistically significant reduction of recurrent cardiovascular events in a high-risk population (135).

An early hint that continuous systemic anti-inflammatory treatment might reduce the cardiovascular risk of psoriasis came from a retrospective study by Prodanovich et al. who analyzed the files of more than 7,000 American veterans who had been treated over extended periods of time with methotrexate for their psoriasis. They found a significantly reduced incidence of cardiovascular diseases in those patients (136). Since then, several observational studies analyzing the effects of methotrexate or TNF- $\alpha$ inhibitors came to similar conclusions (137, 138), while others failed to document such protective effects $(139,140)$. Complementary to these studies, small controlled trials were performed, evaluating changes of biomarkers for cardiovascular risk under systemic anti-psoriatic treatment. Indeed, several groups reported amelioration of such markers under successful therapy. These include cytokines, adipokines, endothelial dysfunction, and carotid intima-media thickness (141-145).

Based on some of these observations, more ambitious projects were launched, sponsored by pharmaceutical companies. A pilot study on 30 psoriasis patients looked at vascular inflammation in the ascending aorta and carotid arteries by means of PET-CTs. In this study, decreases in vascular inflammation were observed in patients treated with adalimumab compared with placebo when data for the ascending aorta and carotid arteries were analyzed separately at 15 weeks (146). A larger study including 107 patients showed no difference over 16 weeks in the adalimumab-treated group compared to placebo and a modest increase in vascular inflammation in the carotid arteries after 52 weeks of treatment with adalimumab (147). A commentary on that publication suggested that the study might have been too small or of insufficient duration to show an effect, and that it was the carotid arteries and ascending aorta that were studied, not the coronary arteries, which might explain the negative result (20). Another study using the IL-17A-blocking antibody secukinumab was performed in a multi-center setting in Germany. A recently presented abstract on the occasion of the congress of the European Academy for Dermatology and Venereology in Geneva in 2017 documented a trend toward improvement in vascular elasticity, but no date from that trial have so far been published in a peer-reviewed manner.

Taken together, there is some evidence in favor of the idea to reduce the excess cardiovascular risk of psoriasis patients through systemic anti-inflammatory therapy. TNF- $\alpha$ and IL-17A are interesting targets in this regard, as the former is an important insulin antagonist, and the latter seems to exhibit primarily proatherogenic effects, although some anti-atherogenic effects have also been reported (148). The CANTOS study can serve as proof of concept for the principal capacity of anti-inflammatory therapy to reduce the cardiovascular risk, but it also points out that even in a high-risk population the effect size might be relatively small. This may explain why much smaller and shorter studies can easily fail to show efficacy in this regard, even more so, if relatively health patients are enrolled, as has been the case in the German trial using secukinumab. Although this approach remains intellectually appealing, it may be more effective and efficient in a 
real-world scenario to address other major cardiovascular risk factors associated with psoriasis in order to reduce the patients' excess cardiovascular risk, e.g., through appropriate treatment of the metabolic syndrome or components thereof, or through lifestyle interventions (smoking!).

\section{CONCLUSION}

Psoriasis is currently regarded a chronic-recurrent, systemic inflammatory disease, driven by an intense cross talk between cells of the innate and adaptive immune system. It is associated with substantial cardiovascular comorbidity, which can only partially be explained through shared a genetic control. Evidence in favor of psoriasis as an independent cardiovascular risk factor comes from epidemiologic studies showing a "dose effect" of psoriasis on the patients' cardiovascular risk as well as from case-control studies looking at biomarkers for cardiovascular risk and specific manifestations of atherosclerosis. Inflammation-induced insulin resistance and endothelial dysfunction provide a pathogenetic

\section{REFERENCES}

1. WHO. Document EB133.R2, Agenda Item 6.2. (2013).

2. Boehncke WH, Schön MP. Psoriasis. Lancet (2015) 386(9997):983-94. doi:10.1016/S0140-6736(14)61909-7

3. Capon F, Burden AD, Trembath RC, Barker JN. Psoriasis and other complex trait dermatoses: from Loci to functional pathways. J Invest Dermatol (2012) 132(3 Pt 2):915-22. doi:10.1038/jid.2011.395

4. Mehta NN, Yu Y, Saboury B, Foroughi N, Krishnamoorthy P, Raper A, et al. Systemic and vascular inflammation in patients with moderate to severe psoriasis as measured by [18F]-fluorodeoxyglucose positron emission tomography-computed tomography (FDG-PET/CT): a pilot study. Arch Dermatol (2011) 147(9):1031-9. doi:10.1001/archdermatol.2011.119

5. Dougados M. Comorbidities in rheumatoid arthritis. Curr Opin Rheumatol (2016) 28(3):282-8. doi:10.1097/BOR.0000000000000267

6. Román AL, Muñoz F. Comorbidity in inflammatory bowel disease. World J Gastroenterol (2011) 17(22):2723-33. doi:10.3748/wjg.v17.i22.2723

7. Wens I, Dalgas U, Stenager E, Eijnde BO. Risk factors related to cardiovascular diseases and the metabolic syndrome in multiple sclerosis - a systematic review. Mult Scler (2013) 19(12):1556-64. doi:10.1177/1352458513504252

8. Takeshita J, Grewal S, Langan SM, Mehta NN, Ogdie A, Van Voorhees AS, et al. Psoriasis and comorbid diseases: epidemiology. J Am Acad Dermatol (2017) 76(3):377-90. doi:10.1016/j.jaad.2016.07.064

9. Boehncke WH. Psoriasis and psoriatic arthritis: flip sides of the coin? Acta Derm Venereol (2016) 96(4):436-41. doi:10.2340/00015555-2385

10. Abuabara K, Azfar RS, Shin DB, Neimann AL, Troxel AB, Gelfand JM. Cause-specific mortality in patients with severe psoriasis: a population-based cohort study in the U.K. Br J Dermatol (2010) 163(3):586-92. doi:10.1111/j.1365-2133.2010.09941.x

11. Agca R, Heslinga SC, Rollefstad S, Heslinga M, McInnes IB, Peters MJ, et al. EULAR recommendations for cardiovascular disease risk management in patients with rheumatoid arthritis and other forms of inflammatory joint disorders: 2015/2016 update. Ann Rheum Dis (2017) 76(1):17-28. doi:10.1136/annrheumdis-2016-209775

12. Stern RS. Psoriasis is not a useful independent risk factor for cardiovascular disease. J Invest Dermatol (2010) 130(4):917-9. doi:10.1038/jid.2009.446

13. Lai YC, Yew YW. Psoriasis as an independent risk factor for cardiovascular disease: an epidemiologic analysis using a national database. JCutan Med Surg (2016) 20(4):327-33. doi:10.1177/1203475415602842

14. Ogdie A, Troxel AB, Mehta NN, Gelfand JM. Psoriasis and cardiovascular risk: strength in numbers part 3. J Invest Dermatol (2015) 135(9):2148-50. doi:10.1038/jid.2015.218

15. Henseler T, Christophers E. Disease concomitance in psoriasis. J Am Acad Dermatol (1995) 32(6):982-6. doi:10.1016/0190-9622(95)91336-X link between psoriasis and atherosclerosis. Whether systemic anti-inflammatory therapy can reduce the patients' excess cardiovascular risk remains one of the hot research topics in the field. Independent of this discussion, a comprehensive approach to the management of psoriasis at least in patients with severe disease is mandatory based on current knowledge. This must include regular screening and monitoring of traditional cardiovascular risk factors as well as their guideline-oriented treatment.

\section{AUTHOR CONTRIBUTIONS}

W-HB is the sole author of this manuscript. He defined the content, performed the literature search, wrote the text, and created figures and the table.

\section{FUNDING}

W-HB is supported by grant 310030_175470/1 from the Swiss National Foundation.

16. Dowlatshahi EA, Kavousi M, Nijsten T, Ikram MA, Hofman A, Franco OH, et al. Psoriasis is not associated with atherosclerosis and incident cardiovascular events: the Rotterdam Study. J Invest Dermatol (2013) 133(10):2347-54. doi:10.1038/jid.2013.131

17. Parisi R, Rutter MK, Lunt M, Young HS, Symmons DPM, Griffiths CEM, et al. Psoriasis and the risk of major cardiovascular events: cohort study using the clinical practice research datalink. J Invest Dermatol (2015) 135(9):2189-97. doi:10.1038/jid.2015.87

18. Egeberg A, Thyssen JP, Jensen P, Gislason GH, Skov L. Risk of myocardial infarction in patients with psoriasis and psoriatic arthritis: a nationwide cohort study. Acta Derm Venereol (2017) 97(7):819-24. doi:10.2340/ 00015555-2657

19. Raaby L, Ahlehoff O, de Thurah A. Psoriasis and cardiovascular events: updating the evidence. Arch Dermatol Res (2017) 309(3):225-8. doi:10.1007/ s00403-016-1712-1

20. Lebwohl M. Does treatment of psoriasis reduce cardiovascular comorbidities? J Invest Dermatol (2017) 137(8):1612-3. doi:10.1016/j.jid. 2017.06.001

21. Nast A, Gisondi P, Ormerod AD, Saiag P, Smith C, Spuls PI, et al. European S3-Guidelines on the systemic treatment of psoriasis vulgaris - Update 2015 - Short version - EDF in cooperation with EADV and IPC. J Eur Acad Dermatol Venereol (2015) 29(12):2277-94. doi:10.1111/jdv.13354

22. Coates LC, Kavanaugh A, Mease PJ, Soriano ER, Laura Acosta-Felquer M, Armstrong AW, et al. Group for research and assessment of psoriasis and psoriatic arthritis 2015 treatment recommendations for psoriatic arthritis. Arthritis Rheumatol (2016) 68(5):1060-71. doi:10.1002/art.39573

23. Armstrong EJ, Harskamp CT, Armstrong AW. Psoriasis and major adverse cardiovascular events: a systematic review and meta-analysis of observational studies. J Am Heart Assoc (2013) 2(2):e000062. doi:10.1161/ JAHA.113.000062

24. Gaeta M, Castelvecchio S, Ricci C, Pigatto P, Pellissero G, Cappato R. Role of psoriasis as independent predictor of cardiovascular disease: a meta-regression analysis. Int J Cardiol (2013) 168(3):2282-8. doi:10.1016/j. ijcard.2013.01.197

25. Gu WJ, Weng CL, Zhao YT, Liu QH, Yin RX. Psoriasis and risk of cardiovascular disease: a meta-analysis of cohort studies. Int J Cardiol (2013) 168(5):4992-6. doi:10.1016/j.ijcard.2013.07.127

26. Horreau C, Pouplard C, Brenaut E, Barnetche T, Misery L, Cribier B, et al. Cardiovascular morbidity and mortality in psoriasis and psoriatic arthritis: a systematic literature review. J Eur Acad Dermatol Venereol (2013) 27(Suppl 3):12-29. doi:10.1111/jdv.12163

27. Miller IM, Ellervik C, Yazdanyar S, Jemec GB. Meta-analysis of psoriasis, cardiovascular disease, and associated risk factors. J Am Acad Dermatol (2013) 69(6):1014-24. doi:10.1016/j.jaad.2013.06.053 
28. Pietrzak A, Bartosińska J, Chodorowska G, Szepietowski JC, Paluszkiewicz P, Schwartz RA. Cardiovascular aspects of psoriasis: an updated review. Int J Dermatol (2013) 52(2):153-62. doi:10.1111/j.1365-4632.2012.05584.x

29. Samarasekera EJ, Neilson JM, Warren RB, Parnham J, Smith CH. Incidence of cardiovascular disease in individuals with psoriasis: a systematic review and meta-analysis. J Invest Dermatol (2013) 133(10):2340-6. doi:10.1038/ jid.2013.149

30. Xu T, Zhang YH. Association of psoriasis with stroke and myocardial infarction: meta-analysis of cohort studies. Br J Dermatol (2012) 167(6): 1345-50. doi:10.1111/bjd.12002

31. Strauss H. Zur Lehre von der neurogenen und der thyreogenen Glykosurie. DtscMed Wochenschr (1897) 20:309-12. doi:10.1055/s-0029-1204995

32. Kassi E, Pervanidou P, Kaltsas G, Chrousos G. Metabolic syndrome: definitions and controversies. BMC Med (2011) 9:48. doi:10.1186/17417015-9-48

33. D’Agostino RB Sr, Vasan RS, Pencina MJ, Wolf PA, Cobain M, Massaro JM, et al. General cardiovascular risk profile for use in primary care: the Framingham Heart Study. Circulation (2008) 117(6):743-53. doi:10.1161/ CIRCULATIONAHA.107.699579

34. Lee EJ, Han KD, Han JH, Lee JH. Smoking and risk of psoriasis: a nationwide cohort study. J Am Acad Dermatol (2017) 77(3):573-5. doi:10.1016/j. jaad.2017.04.015

35. Danielsen K, Wilsgaard T, Olsen AO, Furberg AS. Overweight and weight gain predict psoriasis development in a population-based cohort. Acta Derm Venereol (2017) 97(3):332-9. doi:10.2340/00015555-2530

36. Gelfand JM, Neimann AL, Shin DB, Wang X, Margolis DJ, Troxel AB. Risk of myocardial infarction in patients with psoriasis. JAMA (2006) 296(14):1735-41. doi:10.1001/jama.296.14.1735

37. Armstrong AW, Harskamp CT, Ledo L, Rogers JH, Armstrong EJ. Coronary artery disease in patients with psoriasis referred for coronary angiography. Am J Cardiol (2012) 109(7):976-80. doi:10.1016/j.amjcard.2011.11.025

38. LiWQ, Han JL, Manson JE, Rimm EB, Rexrode KM, Curhan GC, et al. Psoriasis and risk of nonfatal cardiovascular disease in U.S. women: a cohort study. Br J Dermatol (2012) 166(4):811-8. doi:10.1111/j.1365-2133.2011.10774.x

39. Ludwig RJ, Herzog C, Rostock A, Ochsendorf FR, Zollner TM, Thaci D, et al. Psoriasis: a possible risk factor for development of coronary artery calcification. Br J Dermatol (2007) 156(2):271-6. doi:10.1111/j.1365-2133. 2006.07562.x

40. Mehta NN, Yu Y, Pinnelas R, Krishnamoorthy P, Shin DB, Troxel AB, et al. Attributable risk estimate of severe psoriasis on major cardiovascular events. Am J Med (2011) 124(8):775.e1-6. doi:10.1016/j.amjmed.2011.03.028

41. AhlehoffO, Gislason GH, Charlot M, Jørgensen CH, Lindhardsen J, Olesen JB, et al. Psoriasis is associated with clinically significant cardiovascular risk: a Danish nationwide cohort study. J Intern Med (2011) 270(2):147-57. doi:10.1111/j.1365-2796.2010.02310.x

42. Ogdie A, Yu Y, Haynes K, Love TJ, Maliha S, Jiang Y, et al. Risk of major cardiovascular events in patients with psoriatic arthritis, psoriasis and rheumatoid arthritis: a population-based cohort study. Ann Rheum Dis (2015) 74(2):326-32. doi:10.1136/annrheumdis-2014-205675

43. Thyssen JP, Halling-Overgaard AS, Andersen YMF, Gislason G, Skov L, Egeberg A. The association between cardiovascular disease and type 2 diabetes in adults with atopic dermatitis: a systematic review and meta-analysis. Br J Dermatol (2017). doi:10.1111/bjd.16215

44. Andersen YM, Egeberg A, Gislason GH, Hansen PR, Skov L, Thyssen JP. Risk of myocardial infarction, ischemic stroke, and cardiovascular death in patients with atopic dermatitis. J Allergy Clin Immunol (2016) 138(1):310-2. e3. doi:10.1016/j.jaci.2016.01.015

45. Elder JT, Nair RP, Guo SW, Henseler T, Christophers E, Voorhees JJ. The genetics of psoriasis. Arch Dermatol (1994) 130(2):216-24. doi:10.1001/ archderm.1994.01690020082014

46. Nair RP, Stuart PE, Nistor I, Hiremagalore R, Chia NV, Jenisch S, et al. Sequence and haplotype analysis supports HLA-C as the psoriasis susceptibility 1 gene. Am J Hum Genet (2006) 78(5):827-51. doi:10.1086/503821

47. Harden JL, Krueger JG, Bowcock AM. The immunogenetics of psoriasis: a comprehensive review. J Autoimmun (2015) 64:66-73. doi:10.1016/j. jaut.2015.07.008

48. Weidinger S, Willis-Owen SA, Kamatani Y, Baurecht H, Morar N, Liang L, et al. A genome-wide association study of atopic dermatitis identifies loci with overlapping effects on asthma and psoriasis. Hum Mol Genet (2013) 22(23):4841-56. doi:10.1093/hmg/ddt317

49. Tamari M, Saeki H, Hayashi M, Umezawa Y, Ito T, Fukuchi O, et al. An association study of 36 psoriasis susceptibility loci for psoriasis vulgaris and atopic dermatitis in a Japanese population. J Dermatol Sci (2014) 76(2):156-7. doi:10.1016/j.jdermsci.2014.08.005

50. Kim K, Bang SY, Lee HS, Bae SC. Update on the genetic architecture of rheumatoid arthritis. Nat Rev Rheumatol (2017) 13(1):13-24. doi:10.1038/ nrrheum.2016.176

51. Kessler T, Vilne B, Schunkert H. The impact of genome-wide association studies on the pathophysiology and therapy of cardiovascular disease. EMBO Mol Med (2016) 8(7):688-701. doi:10.15252/emmm.201506174

52. Parkes M, Cortes A, van Heel DA, Brown MA. Genetic insights into common pathways and complex relationships among immune-mediated diseases. Nat Rev Genet (2013) 14(9):661-73. doi:10.1038/nrg3502

53. Ellinghaus D, Ellinghaus E, Nair RP, Stuart PE, Esko T, Metspalu A, et al. Combined analysis of genome-wide association studies for Crohn disease and psoriasis identifies seven shared susceptibility loci. Am J Hum Genet (2012) 90(4):636-47. doi:10.1016/j.ajhg.2012.02.020

54. Ellinghaus D, Jostins L, Spain SL, Cortes A, Bethune J, Han B, et al. Analysis of five chronic inflammatory diseases identifies 27 new associations and highlights disease-specific patterns at shared loci. Nat Genet (2016) 48(5):510-8. doi:10.1038/ng.3528

55. Cheng H, Li Y, Zuo XB, Tang HY, Tang XF, Gao JP, et al. Identification of a missense variant in LNPEP that confers psoriasis risk. J Invest Dermatol (2014) 134(2):359-65. doi:10.1038/jid.2013.317

56. Gupta Y, Möller S, Zillikens D, Boehncke WH, Ibrahim SM, Ludwig RJ. Genetic control of psoriasis is relatively distinct from that of metabolic syndrome and coronary artery disease. Exp Dermatol (2013) 22(8):552-3. doi:10.1111/exd.12192

57. Boehncke WH, Schön MP. Animal models of psoriasis. Clin Dermatol (2007) 25(6):596-605. doi:10.1016/j.clindermatol.2007.08.014

58. Hagert C, Sareila O, Kelkka T, Jalkanen S, Holmdahl R. The macrophage mannose receptor regulate mannan-induced psoriasis, psoriatic arthritis, and rheumatoid arthritis-like disease models. Front Immunol (2018) 9:114. doi:10.3389/fimmu.2018.00114

59. Jin SP, Koh SJ, Yu DA, Kim MW, Yun HT, Lee DH, et al. Imiquimodapplied interleukin-10 deficient mice better reflects severe and persistent psoriasis with systemic inflammatory state. Exp Dermatol (2018) 27(1):43-9. doi:10.1111/exd.13403

60. Shibata S, Tada Y, Hau CS, Mitsui A, Kamata M, Asano Y, et al. Adiponectin regulates psoriasiform skin inflammation by suppressing IL-17 production from $\gamma \delta$-T cells. Nat Commun (2015) 6:7687. doi:10.1038/ncomms8687

61. Sherlock JP, Joyce-Shaikh B, Turner SP, Chao CC, Sathe M, Grein J, et al. IL-23 induces spondyloarthropathy by acting on ROR- $\gamma \mathrm{t}+\mathrm{CD} 3+\mathrm{CD} 4-\mathrm{CD} 8$ entheseal resident T cells. Nat Med (2012) 18(7):1069-76. doi:10.1038/ nm.2817

62. Hansson GK. Inflammation, atherosclerosis, and coronary artery disease. $N$ Engl J Med (2005) 352(16):1685-95. doi:10.1056/NEJMra043430

63. Hansson GK. Inflammation and atherosclerosis: the end of a controversy. Circulation (2017) 136(20):1875-7. doi:10.1161/CIRCULATIONAHA. 117.030484

64. Schön MP, Boehncke WH. Psoriasis. N Engl J Med (2005) 352(18):1899-912. doi:10.1056/NEJMra041320

65. Lowes MA, Suárez-Fariñas M, Krueger JG. Immunology of psoriasis. Annu Rev Immunol (2014) 32:227-55. doi:10.1146/annurev-immunol-032713120225

66. Späh F. Inflammation in atherosclerosis and psoriasis: common pathogenic mechanisms and the potential for an integrated treatment approach. Br J Dermatol (2008) 159(Suppl 2):10-7. doi:10.1111/j.1365-2133.2008. 08780.x

67. Boehncke WH, Schön MP. Interfering with leukocyte rolling - a promising therapeutic approach in inflammatory skin disorders? Trends Pharmacol Sci (2003) 24(2):49-52. doi:10.1016/S0165-6147(02)00039-1

68. Boehncke WH, Schön MP, Girolomoni G, Griffiths C, Bos JD, ThestrupPedersen K. Leukocyte extravasation as a target for anti-inflammatory therapy - which molecule to choose? Exp Dermatol (2005) 14(1):70-80. doi:10.1111/j.0906-6705.2005.290a.x 
69. Stemme S, Faber B, Holm J, Wiklund O, Witztum JL, Hansson GK. $\mathrm{T}$ lymphocytes from human atherosclerotic plaques recognize oxidized low density lipoprotein. Proc Natl Acad Sci U S A (1995) 92(9):3893-7. doi:10.1073/pnas.92.9.3893

70. Frostegård J, Ulfgren AK, Nyberg P, Hedin U, Swedenborg J, Andersson U, et al. Cytokine expression in advanced human atherosclerotic plaques: dominance of pro-inflammatory (Th1) and macrophage-stimulating cytokines. Atherosclerosis (1999) 145(1):33-43. doi:10.1016/S00219150(99)00011-8

71. MetheH, Brunner S, Wiegand D, Nabauer M, Koglin J, Edelman ER. Enhanced T-helper-1 lymphocyte activation patterns in acute coronary syndromes. J Am Coll Cardiol (2005) 45(12):1939-45. doi:10.1016/j.jacc.2005.03.040

72. Cheng X, Yu X, Ding YJ, Fu QQ, Xie JJ, Tang TT, et al. The Th17/Treg imbalance in patients with acute coronary syndrome. Clin Immunol (2008) 127(1):89-97. doi:10.1016/j.clim.2008.01.009

73. Hashmi S, Zeng QT. Role of interleukin-17 and interleukin-17-induced cytokines interleukin- 6 and interleukin- 8 in unstable coronary artery disease. Coron Artery Dis (2006) 17(8):699-706. doi:10.1097/01.mca. 0000236288.94553.b4

74. Erbel C, Chen L, Bea F, Wangler S, Celik S, Lasitschka F, et al. Inhibition of IL-17A attenuates atherosclerotic lesion development in apoE-deficient mice. J Immunol (2009) 183(12):8167-75. doi:10.4049/jimmunol.0901126

75. Nickoloff BJ. Skin innate immune system in psoriasis: friend or foe? J Clin Invest (1999) 104(9):1161-4. doi:10.1172/JCI8633

76. Girolomoni G, Strohal R, Puig L, Bachelez H, Barker J, Boehncke WH, et al. The role of IL-23 and the IL-23/ $\mathrm{T}_{\mathrm{H}} 17$ immune axis in the pathogenesis and treatment of psoriasis. J Eur Acad Dermatol Venereol (2017) 31(10):1616-26. doi:10.1111/jdv.14433

77. Mueller W, Herrmann B. Cyclosporin A for psoriasis. N Engl J Med (1979) 301(10):555. doi:10.1056/NEJM197909063011015

78. Lorthois I, Asselineau D, Seyler N, Pouliot R. Contribution of in vivo and organotypic 3D models to understanding the role of macrophages and neutrophils in the pathogenesis of psoriasis. Mediators Inflamm (2017) 2017:7215072. doi:10.1155/2017/7215072

79. Reich K, Papp KA, Matheson RT, Tu JH, Bissonnette R, Bourcier M, et al. Evidence that a neutrophil-keratinocyte crosstalk is an early target of IL-17A inhibition in psoriasis. Exp Dermatol (2015) 24(7):529-35. doi:10.1111/ exd. 12710

80. Soehnlein O. Multiple roles for neutrophils in atherosclerosis. Circ Res (2012) 110(6):875-88. doi:10.1161/CIRCRESAHA.111.257535

81. van Leeuwen M, Gijbels MJ, Duijvestijn A, Smook M, van de Gaar MJ, Heeringa P, et al. Accumulation of myeloperoxidase-positive neutrophils in atherosclerotic lesions in LDLR-/- mice. Arterioscler Thromb Vasc Biol (2008) 28(1):84-9. doi:10.1161/ATVBAHA.107.154807

82. Rotzius $\mathrm{P}$, Thams $\mathrm{S}$, Soehnlein O, Kenne E, Tseng CN, Björkström NK, et al. Distinct infiltration of neutrophils in lesion shoulders in ApoE-/- mice. Am J Pathol (2010) 177(1):493-500. doi:10.2353/ajpath.2010.090480

83. Hosokawa T, Kumon Y, Kobayashi T, Enzan H, Nishioka Y, Yuri K, et al. Neutrophil infiltration and oxidant-production in human atherosclerotic carotid plaques. Histol Histopathol (2011) 26(1):1-11. doi:10.14670/HH-26.1

84. Kramer MC, Rittersma SZ, de Winter RJ, Ladich ER, Fowler DR, Liang YH, et al. Relationship of thrombus healing to underlying plaque morphology in sudden coronary death. J Am Coll Cardiol (2010) 55(2):122-32. doi:10.1016/j. jacc.2009.09.007

85. Deng Y, Chang C, Lu Q. The inflammatory response in psoriasis: a comprehensive review. Clin Rev Allergy Immunol (2016) 50(3):377-89. doi:10.1007/ s12016-016-8535-x

86. Costa S, Marini O, Bevilacqua D, DeFranco AL, Hou B, Lonardi S, et al. Role of MyD88 signaling in the imiquimod-induced mouse model of psoriasis: focus on innate myeloid cells. J Leukoc Biol (2017) 102(3):791-803. doi:10.1189/jlb.3MA0217-054RR

87. Tabas I, Lichtman AH. Monocyte-macrophages and T cells in atherosclerosis. Immunity (2017) 47(4):621-34. doi:10.1016/j.immuni.2017.09.008

88. Peled M, Fisher EA. Dynamic aspects of macrophage polarization during atherosclerosis progression and regression. Front Immunol (2014) 5:579. doi:10.3389/fimmu.2014.00579

89. Tamagawa-Mineoka R. Important roles of platelets as immune cells in the skin. J Dermatol Sci (2015) 77(2):93-101. doi:10.1016/j.jdermsci.2014.10.003
90. Garbaraviciene J, Diehl S, Varwig D, Bylaite M, Ackermann H, Ludwig RJ, et al. Platelet P-selectin reflects a state of cutaneous inflammation: possible application to monitor treatment efficacy in psoriasis. Exp Dermatol (2010) 19(8):736-41. doi:10.1111/j.1600-0625.2010.01095.x

91. Ludwig RJ, Schultz JE, Boehncke WH, Podda M, Tandi C, Krombach F, et al. Activated, not resting, platelets increase leukocyte rolling in murine skin utilizing a distinct set of adhesion molecules. J Invest Dermatol (2004) 122(3):830-6. doi:10.1111/j.0022-202X.2004.22318.x

92. Gawaz M, Langer H, May AE. Platelets in inflammation and atherogenesis. J Clin Invest (2005) 115(12):3378-84. doi:10.1172/JCI27196

93. Gisterå A, Hansson GK. The immunology of atherosclerosis. Nat Rev Nephrol (2017) 13(6):368-80. doi:10.1038/nrneph.2017.51

94. Jamasbi J, Ayabe K, Goto S, Nieswandt B, Peter K, Siess W. Platelet receptors as therapeutic targets: past, present and future. Thromb Haemost (2017) 117(7):1249-57. doi:10.1160/TH16-12-0911

95. Croxford AL, Karbach S, Kurschus FC, Wörtge S, Nikolaev A, Yogev N, et al. IL-6 regulates neutrophil microabscess formation in IL-17A-driven psoriasiform lesions. J Invest Dermatol (2014) 134(3):728-35. doi:10.1038/ jid.2013.404

96. Amin M, Darji K, No DJ, Bhutani T, Wu JJ. Review of IL-17 inhibitors for psoriasis. J Dermatolog Treat (2017) 10:1-6. doi:10.1080/09546634.2017. 1395796

97. Gao Q, Jiang Y, Ma T, Zhu F, Gao F, Zhang P, et al. A critical function of Th17 proinflammatory cells in the development of atherosclerotic plaque in mice. J Immunol (2010) 185(10):5820-7. doi:10.4049/jimmunol.1000116

98. Smith E, Prasad KM, Butcher M, Dobrian A, Kolls JK, Ley K, et al. Blockade of interleukin-17A results in reduced atherosclerosis in apolipoprotein E-deficient mice. Circulation (2010) 121(15):1746-55. doi:10.1161/ CIRCULATIONAHA.109.924886

99. Madhur MS, Funt SA, Li L, Vinh A, Chen W, Lob HE, et al. Role of interleukin 17 in inflammation, atherosclerosis, and vascular function in apolipoprotein e-deficient mice. Arterioscler Thromb Vasc Biol (2011) 31(7):1565-72. doi:10.1161/ATVBAHA.111.227629

100. Erbel C, Akhavanpoor M, Okuyucu D, Wangler S, Dietz A, Zhao L, et al. IL-17A influences essential functions of the monocyte/macrophage lineage and is involved in advanced murine and human atherosclerosis. J Immunol (2014) 193(9):4344-55. doi:10.4049/jimmunol.1400181

101. Taleb S, Romain M, Ramkhelawon B, Uyttenhove C, Pasterkamp G, Herbin O, et al. Loss of SOCS3 expression in T cells reveals a regulatory role for interleukin-17 in atherosclerosis. J Exp Med (2009) 206(10):2067-77. doi:10.1084/jem. 20090545

102. Simon T, Taleb S, Danchin N, Laurans L, Rousseau B, Cattan S, et al. Circulating levels of interleukin-17 and cardiovascular outcomes in patients with acute myocardial infarction. Eur Heart J (2013) 34(8):570-7. doi:10.1093/eurhearti/ehs263

103. Strober B, Teller C, Yamauchi P, Miller JL, Hooper M, Yang YC, et al. Effects of etanercept on C-reactive protein levels in psoriasis and psoriatic arthritis. Br J Dermatol (2008) 159(2):322-30. doi:10.1111/j.13652133.2008.08628.x

104. Kanelleas A, Liapi C, Katoulis A, Stavropoulos P, Avgerinou G, Georgala S, et al. The role of inflammatory markers in assessing disease severity and response to treatment in patients with psoriasis treated with etanercept. Clin Exp Dermatol (2011) 36(8):845-50. doi:10.1111/j.1365-2230.2011.04131.x

105. Kim JA, Montagnani M, Koh KK, Quon MJ. Reciprocal relationships between insulin resistance and endothelial dysfunction: molecular and pathophysiological mechanisms. Circulation (2006) 113(15):1888-904. doi:10.1161/CIRCULATIONAHA.105.563213

106. Reaven GM. Role of insulin resistance in human disease (syndrome X): an expanded definition. Annu Rev Med (1993) 44:121-31. doi:10.1146/annurev. me.44.020193.001005

107. McVeigh GE, Cohn JN. Endothelial dysfunction and the metabolic syndrome. Curr Diab Rep (2003) 3(1):87-92. doi:10.1007/s11892-003-0059-0

108. Montagnani M, Quon MJ. Insulin action in vascular endothelium: potential mechanisms linking insulin resistance with hypertension. Diabetes Obes Metab (2000) 2(5):285-92. doi:10.1046/j.1463-1326.2000.00092.x

109. Kim JA, Koh KK, Quon MJ. The union of vascular and metabolic actions of insulin in sickness and in health. Arterioscler Thromb Vasc Biol (2005) 25(5):889-91. doi:10.1161/01.ATV.0000164044.42910.6b 
110. Hotamisligil GS, Shargill NS, Spiegelman BM. Adipose expression of tumor necrosis factor-alpha: direct role in obesity-linked insulin resistance. Science (1993) 259(5091):87-91. doi:10.1126/science.7678183

111. Boehncke WH, Boehncke S, Schön MP. Managing comorbid disease in patients with psoriasis. BMJ (2010) 340:b5666. doi:10.1136/bmj.b5666

112. Boehncke WH, Boehncke S, Tobin AM, Kirby B. The 'psoriatic march': a concept of how severe psoriasis may drive cardiovascular comorbidity. Exp Dermatol (2011) 20(4):303-7. doi:10.1111/j.1600-0625.2011.01261.x

113. BoehnckeS, Thaci D, Beschmann H, Ludwig RJ, Ackermann H, Badenhoop K, et al. Psoriasis patients show signs of insulin resistance. Br J Dermatol (2007) 157(6):1249-51. doi:10.1111/j.1365-2133.2007.08190.x

114. Cerman AA, Bozkurt S, Sav A, Tulunay A, Elbaşi MO, Ergun T. Serum leptin levels, skin leptin and leptin receptor expression in psoriasis. Br J Dermatol (2008) 159(4):820-6. doi:10.1111/j.1365-2133.2008.08742.x

115. Matthews DR, Hosker JP, Rudenski AS, Naylor BA, Treacher DF, Turner RC. Homeostasis model assessment: insulin resistance and beta-cell function from fasting plasma glucose and insulin concentrations in man. Diabetologia (1985) 28(7):412-9. doi:10.1007/BF00280883

116. National Diabetes Data Group. Classification and diagnosis of diabetes mellitus and other categories of glucose intolerance. National Diabetes Data Group. Diabetes (1979) 28(12):1039-57. doi:10.2337/diab.28.12.1039

117. Ucak S, Ekmekci TR, Basat O, Koslu A, Altuntas Y. Comparison of various insulin sensitivity indices in psoriatic patients and their relationship with type of psoriasis. JEur Acad Dermatol Venereol (2006) 20(5):517-22. doi:10.1111/j.1468-3083.2006.01499.x

118. Lago R, Gómez R, Lago F, Gómez-Reino J, Gualillo O. Leptin beyond body weight regulation - current concepts concerning its role in immune function and inflammation. Cell Immunol (2008) 252(1-2):139-45. doi:10.1016/j. cellimm.2007.09.004

119. Gisondi P, Fantin F, Del Giglio M, Valbusa F, Marino F, Zamboni M, et al. Chronic plaque psoriasis is associated with increased arterial stiffness. Dermatology (2009) 218(2):110-3. doi:10.1159/000182256

120. Balci DD, Balci A, Karazincir S, Ucar E, Iyigun U, Yalcin F, et al. Increased carotid artery intima-media thickness and impaired endothelial function in psoriasis. JEur Acad Dermatol Venereol (2009) 23(1):1-6. doi:10.1111/j.1468-3083.2008.02936.x

121. Ulusoy RE, Karabudak O, Yokusoglu M, Kilicaslan F, Kirilmaz A, Cebeci BS. Noninvasive assessment of impaired endothelial function in psoriasis. Rheumatol Int (2010) 30(4):479-83. doi:10.1007/s00296-009-0995-3

122. Karadag AS, Yavuz B, Ertugrul DT, Akin KO, Yalcin AA, Deveci OS, et al. Is psoriasis a pre-atherosclerotic disease? Increased insulin resistance and impaired endothelial function in patients with psoriasis. Int J Dermatol (2010) 49(6):642-6. doi:10.1111/j.1365-4632.2009.04358.x

123. Buerger C, Richter B, Woth K, Salgo R, Malisiewicz B, Diehl S, et al. Interleukin- $1 \beta$ interferes with epidermal homeostasis through induction of insulin resistance: implications for psoriasis pathogenesis. J Invest Dermatol (2012) 132(9):2206-14. doi:10.1038/jid.2012.123

124. Buerger C, Shirsath N, Lang V, Berard A, Diehl S, Kaufmann R, et al. Inflammation dependent mTORC1 signaling interferes with the switch from keratinocyte proliferation to differentiation. PLoS One (2017) 12(7):e0180853. doi:10.1371/journal.pone.0180853

125. Malisiewicz B, Boehncke S, Lang V, Boehncke WH, Buerger C. Epidermal insulin resistance as a therapeutic target in acanthosis nigricans? Acta Derm Venereol (2014) 94(5):607-8. doi:10.2340/00015555-1778

126. Parsi KK, Brezinski EA, Lin TC, Li CS, Armstrong AW. Are patients with psoriasis being screened for cardiovascular risk factors? A study of screening practices and awareness among primary care physicians and cardiologists. J Am Acad Dermatol (2012) 67(3):357-62. doi:10.1016/j. jaad.2011.09.006

127. Alamdari HS, Gustafson CJ, Davis SA, Huang W, Feldman SR. Psoriasis and cardiovascular screening rates in the United States. J Drugs Dermatol (2013) 12(1):e14-9.

128. Takeshita J, Wang S, Shin DB, Mehta NN, Kimmel SE, Margolis DJ, et al. Effect of psoriasis severity on hypertension control: a population-based study in the United Kingdom. JAMA Dermatol (2015) 151(2):161-9. doi:10.1001/ jamadermatol.2014.2094

129. Kimball AB, Gladman D, Gelfand JM, Gordon K, Horn EJ, Korman NJ, et al. National Psoriasis Foundation clinical consensus on psoriasis comorbidities and recommendations for screening. J Am Acad Dermatol (2008) 58(6):1031-42. doi:10.1016/j.jaad.2008.01.006

130. Daudén E, Castañeda S, Suárez C, García-Campayo J, Blasco AJ, Aguilar MD, et al. Clinical practice guideline for an integrated approach to comorbidity in patients with psoriasis. J Eur Acad Dermatol Venereol (2013) 27(11): 1387-404. doi:10.1111/jdv.12024

131. Radtke MA, Mrowietz U, Feuerhahn J, Härter M, von Kiedrowski R, Nast A, et al. Early detection of comorbidity in psoriasis: recommendations of the National Conference on Healthcare in Psoriasis. J Dtsch Dermatol Ges (2015) 13(7):674-90. doi:10.1111/ddg. 12643

132. Takeshita J, Grewal S, Langan SM, Mehta NN, Ogdie A, Van Voorhees AS, et al. Psoriasis and comorbid diseases: implications for management. J Am Acad Dermatol (2017) 76(3):393-403. doi:10.1016/j.jaad.2016.07.065

133. Goff DC Jr, Lloyd-Jones DM, Bennett G, Coady S, D'Agostino RB Sr, Gibbons R, et al. 2013 ACC/AHA guideline on the assessment of cardiovascular risk: a report of the American College of Cardiology/American Heart Association Task Force on Practice Guidelines. J Am Coll Cardiol (2014) 63(25 Pt B):2935-59. doi:10.1016/j.jacc.2013.11.005

134. Gisondi P, Del Giglio M, Di Francesco V, Zamboni M, Girolomoni G. Weight loss improves the response of obese patients with moderate-to-severe chronic plaque psoriasis to low-dose cyclosporine therapy: a randomized, controlled, investigator-blinded clinical trial. Am J Clin Nutr (2008) 88(5): 1242-7.

135. Ridker PM, Everett BM, Thuren T, MacFadyen JG, Chang WH, Ballantyne C, et al. Antiinflammatory therapy with canakinumab for atherosclerotic disease. N Engl J Med (2017) 377(12):1119-31. doi:10.1056/NEJMoa1707914

136. Prodanovich S, Ma F, Taylor JR, Pezon C, Fasihi T, Kirsner RS. Methotrexate reduces incidence of vascular diseases in veterans with psoriasis or rheumatoid arthritis. JAm Acad Dermatol (2005) 52(2):262-7. doi:10.1016/j. jaad.2004.06.017

137. Wu JJ, Poon KY, Channual JC, Shen AY. Association between tumor necrosis factor inhibitor therapy and myocardial infarction risk in patients with psoriasis. Arch Dermatol (2012) 148(11):1244-50. doi:10.1001/ archdermatol.2012.2502

138. Ahlehoff O, Skov L, Gislason G, Lindhardsen J, Kristensen SL, Iversen L, et al. Cardiovascular disease event rates in patients with severe psoriasis treated with systemic anti-inflammatory drugs: a Danish real-world cohort study. J Intern Med (2013) 273(2):197-204. doi:10.1111/j.1365-2796.2012.02593.x

139. Abuabara K, Lee H, Kimball AB. The effect of systemic psoriasis therapies on the incidence of myocardial infarction: a cohort study. Br J Dermatol (2011) 165(5):1066-73. doi:10.1111/j.1365-2133.2011.10525.x

140. Chen YJ, Chang YT, Shen JL, Chen TT, Wang CB, Chen CM, et al. Association between systemic antipsoriatic drugs and cardiovascular risk in patients with psoriasis with or without psoriatic arthritis: a nationwide cohort study. Arthritis Rheum (2012) 64(6):1879-87. doi:10.1002/art.34335

141. Coimbra S, Oliveira H, Reis F, Belo L, Rocha S, Quintanilha A, et al. Circulating adipokine levels in Portuguese patients with psoriasis vulgaris according to body mass index, severity and therapy. J Eur Acad Dermatol Venereol (2010) 24(12):1386-94. doi:10.1111/j.1468-3083.2010.03647.x

142. Coimbra S, Oliveira H, Reis F, Belo L, Rocha S, Quintanilha A, et al. Interleukin (IL)-22, IL-17, IL-23, IL-8, vascular endothelial growth factor and tumour necrosis factor- $\alpha$ levels in patients with psoriasis before, during and after psoralen-ultraviolet $\mathrm{A}$ and narrowband ultraviolet B therapy. Br J Dermatol (2010) 163(6):1282-90. doi:10.1111/j.1365-2133.2010.09992.x

143. Boehncke S, Fichtlscherer S, Salgo R, Garbaraviciene J, Beschmann H, Diehl S, et al. Systemic therapy of plaque-type psoriasis ameliorates endothelial cell function: results of a prospective longitudinal pilot trial. Arch Dermatol Res (2011) 303(6):381-8. doi:10.1007/s00403-010-1108-6

144. Boehncke S, Salgo R, Garbaraviciene J, Beschmann H, Hardt K, Diehl S, et al. Effective continuous systemic therapy of severe plaque-type psoriasis is accompanied by amelioration of biomarkers of cardiovascular risk: results of a prospective longitudinal observational study. J Eur Acad Dermatol Venereol (2011) 25(10):1187-93. doi:10.1111/j.1468-3083. 2010.03947.x

145. Martinez-Lopez A, Blasco-Morente G, Perez-Lopez I, Tercedor-Sanchez J, Arias-Santiago S. Studying the effect of systemic and biological drugs on intima-media thickness in patients suffering from moderate and severe psoriasis. J Eur Acad Dermatol Venereol (2018). doi:10.1111/jdv.14841 
146. Bissonnette R, Tardif JC, Harel F, Pressacco J, Bolduc C, Guertin MC. Effects of the tumor necrosis factor- $\alpha$ antagonist adalimumab on arterial inflammation assessed by positron emission tomography in patients with psoriasis: results of a randomized controlled trial. Circ Cardiovasc Imaging (2013) 6(1):83-90. doi:10.1161/CIRCIMAGING.112.975730

147. Bissonnette R, Harel F, Krueger JG, Guertin MC, Chabot-Blanchet M, Gonzalez J, et al. TNF- $\alpha$ antagonist and vascular inflammation in patients with psoriasis vulgaris: a randomized placebo-controlled study. J Invest Dermatol (2017) 137(8):1638-45. doi:10.1016/j.jid.2017.02.977

148. Gong F, Liu Z, Liu J, Zhou P, Liu Y, Lu X. The paradoxical role of IL-17 in atherosclerosis. Cell Immunol (2015) 297(1):33-9. doi:10.1016/j.cellimm. 2015.05.007
Conflict of Interest Statement: The author received honoraria as a speaker or advisor from the following companies: Abbvie, Almirall, BMS, Celgene, Janssen, Leo, Lilly, Novartis, Sun Pharmaceuticals, and UCB. The author has received a research grant to study the role of Janus kinases in the pathogenesis of psoriasis from Pfizer. The author is supported by a grant from The Swiss National Foundation (310030_175470/1).

Copyright (c) 2018 Boehncke. This is an open-access article distributed under the terms of the Creative Commons Attribution License (CC BY). The use, distribution or reproduction in other forums is permitted, provided the original author $(s)$ and the copyright owner are credited and that the original publication in this journal is cited, in accordance with accepted academic practice. No use, distribution or reproduction is permitted which does not comply with these terms. 